\title{
Water re-use for sustainable irrigation
}

\author{
G. Perillo \\ Department of Technology, Naples Parthenope University, Italy
}

\begin{abstract}
The wastewater reuse is part of measures to increase the availability of water resources and is combined with measures involving infrastructure for transporting these resources from areas of high availability to others that has not. Based on a mode for the reuse of the resource, is also necessary to identify treatments of aging and their intensity application, which will the water be submitted to become suitable for intended use.

In addition to sanitary aspects, economic, environmental and social factors are not to be underestimated; the economic one, in fact, plays a key role especially in developing countries, because the use of reuse technologies involves financial investments not always affordable.

This paper summarizes the possible applicable technologies for the reuse of wastewater for irrigation purposes, highlighting the aspects previously mentioned and describing a case study.

Keywords: wastewater reuse, treatment systems, irrigation.
\end{abstract}

\section{Introduction}

The constant growth in the urban population, the contamination of surface water and groundwater, the non-uniform distribution of water resources and the frequent droughts caused by climate change are the principal factors determining the present-day problems of water supply and the fall in water quality.

In recent years, the benefits of recycling water have been fully acknowledged by many countries. For instance, the California Water Code clearly states; "It is the intention of the Legislature that the state undertake all possible steps to encourage development of water recycling facilities so that recycled water may be made available to help meet the growing water requirements of the state".

It thus follows that water recycling plays a legitimate and important role in the planning and efficient use of water resources, provided that more attention is 
paid to all issues of public health and environmental conservation and in a framework of greater transparency.

\section{Main uses of recycled water}

Water recycling performs the following two functions:

- Treated effluent is used as a water source for beneficial purposes;

- Effluent is no longer released into waterways, lakes and beaches, bringing about a reduction in the pollution of surface water and groundwater.

The scale of recycling scenarios depends on such factors as hygiene and sanitation, engineering, the economy, the environment and social issues. In planning water recovery and recycling operations, the possibilities for recycling usually determine both the treatment level required in order to safeguard public health and the environment and also the reliability level of the processes involved.

The main use for recycled water is in agriculture, which is currently the most widespread solution and offers the best opportunities for the future. This is followed by the irrigation of parks, golf courses, the central reservation of highways, the green areas around shopping precincts, offices and industrial estates as well as in residential areas.

The third most important use of recycled water lies in industrial activities, in particular to meet the needs of process and cooling operations, which often constitute the only way for recycled water to be used. Considering the wide range of possible uses in the industrial field, it is often necessary to employ more thorough treatment processes than in secondary and conventional applications in order to guarantee water quality levels suitable for their intended reuse [1].

A fourth way in which water can be recycled is to recharge aquifers, which can be achieved both through the use of spreading basins and through the direct injection of water into the aquifers. In this case the water quality characteristics must be comparable to those of the aquifer so that the recycled water can recharge the aquifer or be stored in it for subsequent use or, finally, in order to create hydraulic barriers that will impede saltwater intrusion in coastal areas.

A fifth use for recycled water lies in recreational-environmental interventions, as its quality characteristics may be suitable for the creation of artificial lakes and wetlands or to maintain the flow of waterways, which considerably improves the natural habitat.

A sixth way in which recycled water can be employed, and which does not require the water to be purified, is in such activities as fire protection, air conditioning and sewer cleaning operations.

The first five cases account for relatively large quantities of recycled water, while the sixth is currently fairly small [2]. 


\section{Legislation on recycled water}

Article 12 of the EU Directive 91/271/CEE lays down that waste water must be recycled whenever possible.

As far as the use of recycled water in agriculture is concerned, the World Health Organisation guidelines (WHO, 1989) incorporates the results of numerous research projects and studies on health risks related to the use of recycled waste water. The limitations suggested by WHO are, however, not particularly restrictive and some countries have therefore considered them inadequate, while others have adopted them fully. These limitations stem from the precarious hygiene and sanitary conditions of such countries and it was, therefore, deemed preferable to impose relatively unrestrictive limits rather than leave waste water recycling operations totally unregulated. Moreover, where economic resources are limited, more technological treatments, such as tertiary treatments, are infeasible.

Finally, in the international context, the US Environmental Protection Agency laid down guidelines for recycled water quality (US EPA, 1992).

\section{Sanitary and environmental implications}

Before examining the treatment processes held to be technically valid for producing recycled water, we have considered the sanitary and environmental aspects in order to assess which contaminants have to be removed from the water and to what degree.

The contaminants of municipal waste water subject to treatment can be classified as follows:

- conventional: contaminants, measured in $\mathrm{mg} / \mathrm{l}$, that are considered in the design of conventional waste water treatment plants.

- non-conventional: contaminants that might have to be removed or reduced by means of advanced treatment processes before the water can be used.

- emerging: classes of compounds, measured in micro or nanograms/1, which, depending upon a more thorough investigation, may turn out to be harmful in the long term to health and to the environment; in some cases these compounds cannot be effectively removed even by using advanced processes.

In order to ensure a better overview of the possible health and environmental implications, risk analysis can be employed. This consists of two phases:

1. Risk assessment, i.e. the study and analysis of the potential effects of some hazardous substances on health. This acts as a decision-making tool where available information makes it possible to make a statistical correlation between cause and effect and is performed in four different phases:

A. identification of risk factors: collection of data indicating whether a given substance produces potentially negative effects for health or has an unacceptable environmental impact. 
B. exposure assessment: identification of the potential receptor, assessment of the means of exposure and quantification of the exposure.

C. assessment of the relation between dosage and response: definition of a mathematical relation between the quantity of a toxic contaminant to which a human being is exposed and the risk of a negative response for health, corresponding to the considered dosage.

D. risk characterization: definition of the subjects involved and the probable effects on the basis of the level of knowledge reached.

2. Risk management, which consists of the procedure that allows the risk to be reduced to acceptable levels and calls for the establishment of standards, guidelines and management strategies for specific contaminants, such as toxic compounds and infectious agents.

\section{Waste water treatment systems}

With regard to the benefits and future prospects offered by the possibility of recycling waste water, new technologies aim to define efficient processes that can ensure an economically viable supply of recycled water.

It has been remarked that the quality characteristics of water subjected to recycling treatments depend on the use to which it will subsequently be put. If the waste water recycling scenario envisages frequent exposure to people, treatment processes must ensure no limitations on the use of the recycled water. And it must therefore undergo disinfection and filtration processes [3].

The flow charts of the three main treatment processes employed to obtain effluents of a predetermined quality are reported in figure 1:

- complete treatment,

- direct filtration,

- contact filtration.

When choosing between complete treatment, direct filtration or contact filtration, the discriminating economic factor considered is a turbidity value of $10 \mathrm{NTU}$ in the secondary treatment effluent.

Over the past 10 years a great deal of information has become available on the yield and reliability of both conventional and advanced treatment processes used to remove conventional contaminants from waste water. However, there is relatively little information on the removal of non-conventional and emerging contaminants [4].

The Complete treatment of waste water includes the phases of coagulation, flocculation, clarification, filtration and disinfection, which yields water that is virtually free of solid particles and enteric bacteria and viruses so that it can be used for water supply; a particularly important role in virus removal is performed by the final disinfection unit. The main drawback of this process lies in the higher costs of clariflocculation and sludge management [5].

The direct filtration flow chart is essentially identical to that for complete treatment, with the exception of the clariflocculator. Floc formation takes place 


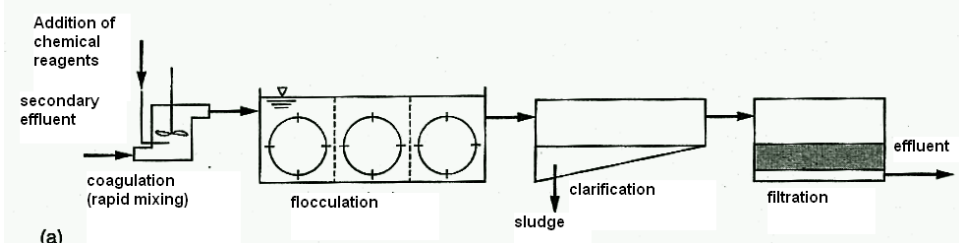

(a)

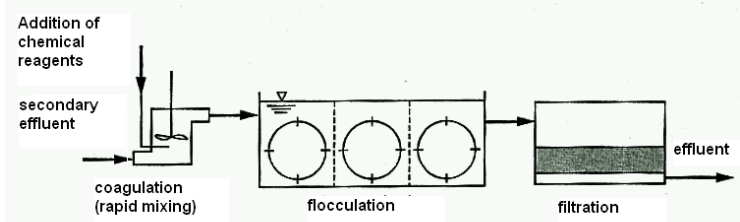

(b)

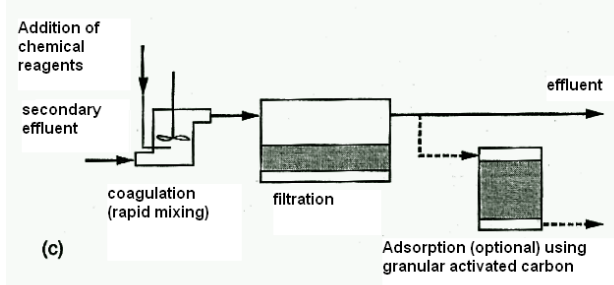

Figure 1: Comparison of tertiary treatment systems for recycling waste water: a) complete treatment, b) direct filtration, c) contact filtration with optional adsorption treatment using activated carbon.

in the flocculation basin with alum and auxiliary coagulation polymers used as additives.

The contact filtration flow chart envisages in-line coagulation upstream from contact filtration. With sufficient contact time for disinfection, it is possible to achieve virus attenuation/disinfection equal to that obtained using the complete treatment.

\section{Reliability of treatment processes}

The reliability of a waste water treatment plant can be assessed on the basis of its ability to produce water with quantitative and qualitative characteristics that are constant over time.

There are two types of problem that may affect the performance and the reliability of a waste water treatment plant:

- the variability of the characteristics of the waste water prior to treatment, which is independent of the design, running and maintenance of the plant. This means that when a waste water treatment and recycling plant is being designed, it is particularly important to define how the waste water quality characteristics will vary over time and to determine how reliable the treatment process will be in dealing with these variations; 
- the inadequacy of design choices and/or an inappropriate management; the poor performance of plants is often attributed to bad management and maintenance of the electromechanical equipment used.

The reliability of a treatment plant is therefore dependant on the intrinsic operational stability of the chosen treatment process but also on the functionality level of the mechanical equipment used $[6,7]$.

\section{Waste water treatment techniques for reuse in agriculture}

Some methods that can be used to yield biologically purified water are illustrated in Figure 2:

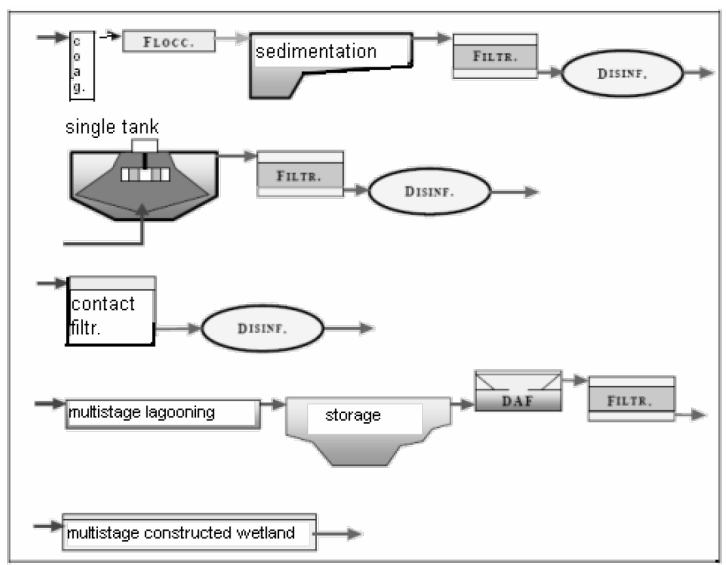

Figure 2: $\quad$ Some methods yielding biologically purified waste water.

- Contact filtration + disinfection: This is currently the most widely used method for almost all potential plant purposes when simplicity, reduced size, reasonable costs and working flexibility are the primary factors considered;

- Natural methods: the use of constructed wetlands appears to be an attractive solution, especially for small-scale plants although there are some examples in Europe where this solution has been applied to medium-size plants (for instance, the Empuriabrava plant in Spain);

- Storage basins: although this is not a treatment system proper, the use of these tanks appears to be highly appropriate for increasing the quantity of recovered water that can be recycled and hence reduce the impact of depreciation on running costs. 
Recycling can also be achieved indirectly by recharging the aquifer with treated water, which is a method enabling the planned increase in groundwater reserves. Two methods are most frequently used for recharging the aquifer (figure 3):

- by means of spreading basins;

- through direct injection into the aquifers.

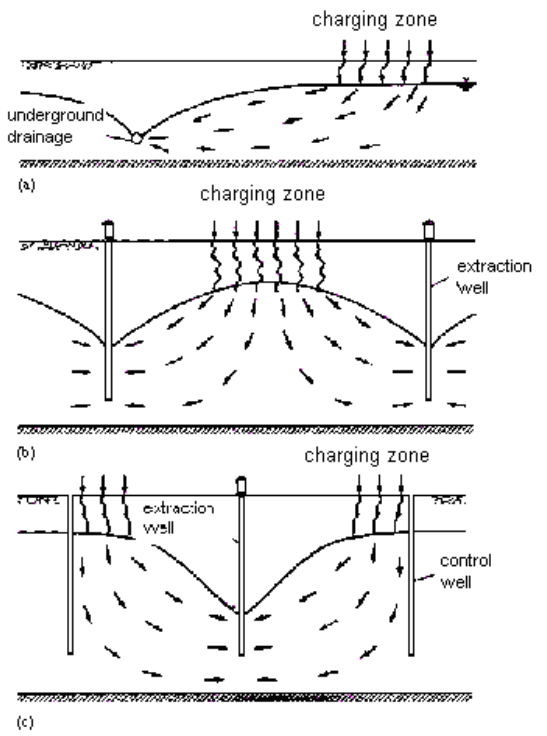

Figure 3: Typical treatment methods using aquifer infiltration systems (SAT) with recycling of treated water by means of (a) underground drainage, (b) wells located around the spreading basins and (c) wells situated between two parallel strips of basins [8].

\section{Case study}

The study focuses on the possible use of treated water from the water treatment plants, Acerra $\left(W T_{A}\right)$, Napoli Nord $\left(W T_{N N}\right)$ and Area Casertana $\left(W T_{A C}\right)$, serving the Province of North Naples (Italy), in order to increase the flow irrigation used by the Consorzio di Bonifica del Bacino Inferiore del Volturno, which irrigates an area of 124006.75 ha and involving 77 municipalities.

The Consorzio derives a capacity of $1,898 \mathrm{~m}^{3} / \mathrm{s}$ from the river Volturno $(F D v)$, but it's often not sufficient to meet the needs of users.

Through the adoption of a system of filtration and disinfection, as well as a series of hydraulic works, whose final hydraulic scheme is shown in figure 4 , it has been possible the use of a supplementary flow of $3.42 \mathrm{~m}^{3} / \mathrm{s}$. 


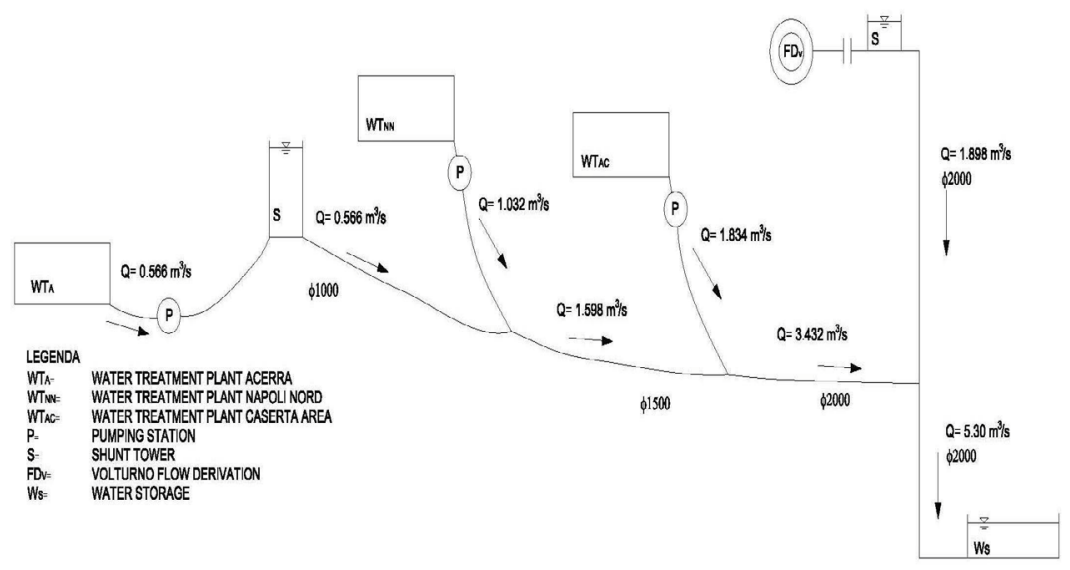

Figure 4: Consorzio hydraulic scheme.

Therefore, the flow rate is equal to $5.30 \mathrm{~m}^{3} / \mathrm{s}$ and allows the regular functioning of the system.

\section{Conclusions}

Although recycling - and the dual systems needed to make it possible - may constitute a useful tool in the planning of water resource usage in order to reduce the consumption of higher quality water, it requires a thorough feasibility analysis that considers technical and economic factors.

In particular, the following steps need to be implemented:

a) identification of alternative sources of supply and assessment of the quality and the quantity of the available resources;

b) identification of the end users and assessment of their requirements: municipal, domestic, agricultural, industrial in technological cycles, environmental (e.g. the creation of recreational areas in towns and aquifer recharging);

c) assessment of the quality level, and hence the treatment processes required, that must be envisaged for the alterative water resource to be used for the intended purposes;

d) sizing of the dual system;

e) technical and economic analysis of the dual system in order to verify its feasibility, taking into account: plant construction, running and maintenance costs; social costs related to any safety measures that need to be implemented (see point g); tariffs, social benefits (limitation of the consumption of higher-quality water resources, reduction in some cases of the waste water to be treated);

f) environmental impact analysis;

g) assessment of safety issues and their related costs: 
- inappropriate water use, perhaps requiring a different colour scheme for the distribution pipelines in the dual network and/or of the non-drinking water;

- network interconnection problems and possible return of the lower quality water into the drinking water system;

h) assessment of the hygiene and sanitation risks related to the recycling of waste water treated in urban areas (infection by pathogenic germs such as Rotavirus and Giardia).

All these changes will require a new culture of water use reflecting a new culture of sustainability with the development of new technologies making it possible to improve the efficiency and quality of water management.

\section{References}

[1] Artina S., Calenda G., Calomino F., La loggia G., Modica C., Paoletti A., Papiri S., Rasulo G., Veltri P., Sistemi di fognatura. Manuale di Progettazione, CSDU - Hoepli, Milano, 1997.

[2] Deletic A., The first flush load of urban surface runoff. Water Research, Volume 32, n. 8, 1998.

[3] De Martino G., De Paola F., Fontana N., Marini G., Ranucci A., Riduzione dell'impatto inquinante delle acque di prima pioggia sui corpi idrici: l'efficienza degli scaricatori di piena. L'Acqua n.4, 2008.

[4] Cupta K., Saul A.J., Specific relationship for the first flush load in combined sewer flow. Water Resources, Vol. 30, n. 5, 1996.

[5] Milano V., Pagliara S., Dellacasa F.. Urban stormwater quantity and quality in the experimental urban catchment of Picchianti, $2^{\text {nd }}$ International Conference. New trends in Water and Environmental Engineering for Safety and life: Eco-compatible Solution for Acquatic Environments, Capri, 2002.

[6] Paoletti A., Papiri S., Sistemi fognari unitary e separate: aspetti funzionali e ambientali. Giornata di studio: La separazione delle acque nelle reti fognarie urbane, Roma, 2003.

[7] G. d'Antonio, G. Perillo, Il riuso delle acque reflue. Convegno: “ L'acqua in più, l'acqua in meno". Caserta, 2007.

[8] G. Perillo, L'utilizzo in agricoltura e nell'industria delle acque derivanti da riutilizzo. Università degli Studi Parthenope, Napoli, 2011. 